\title{
1 Lithospheric layering beneath northern Central Africa by S-to-P receiver functions
}

2 Awad A. Lemnifi', ${ }^{1,}$, Lin Liu ${ }^{3,4}$, John Browning 5

$3 \quad{ }^{1}$ Mining Engineering department, Missouri University of Science and Technology, Rolla, MO, USA.

$4 \quad{ }^{2}$ Department of Earth Science, Faculty of Sciences, Benghazi University, Libya.

$5 \quad{ }^{3}$ Key Laboratory of Submarine Geosciences and Prospecting Techniques, Ministry of Education, College of Marine

6 Geosciences, Ocean University of China, Qingdao, China.

$7 \quad{ }^{4}$ Department of Geophysics, Stanford University, Stanford, CA, USA.

$8{ }^{5}$ Department of Mining Engineering and Department of Structural and Geotechnical Engineering, Pontificia 9 Universidad Catolica de Chile, Santiago, Chile.

11 Corresponding author: Lin Liu (1ltrc@mst.edu)

\section{Abstract} Institutions for Seismology Data Management Center, we imaged the depth of the lithosphereasthenosphere boundary (LAB) beneath northern Central Africa. This boundary occurs over the depth range of 57-124 km which we imaged in consecutive circular bins (radius of $2^{\circ}$ ) using a high number of receiver functions. The mean depth of the discontinuity is $80 \pm 17 \mathrm{~km}$, which is significantly shallower than the global average of $\sim 250 \mathrm{~km}$, commonly found beneath ancient cratons. The SRFs in the study area produced 156 bins with observable arrivals from the LAB. All the stacked traces were plotted along eight latitudinal profiles from $20^{\circ} \mathrm{N}$ to $35^{\circ} \mathrm{N}$. The observed depth of the LAB increases systematically toward the northern central part of the study area from approximately $67 \mathrm{~km}$ to $120 \mathrm{~km}$. The apparent depth of the LAB increases from 70 to $90 \mathrm{~km}$ from $21^{\circ} \mathrm{N}$ to $28^{\circ} \mathrm{N}$ and then further increases to $120 \mathrm{~km}$ from $28^{\circ} \mathrm{N}$ to $34^{\circ} \mathrm{N}$. These depth variations are extreme beneath the northern central part of Libya. The LAB depth 
beneath the Hoggar volcanic province area is relatively low $(\sim 57 \mathrm{~km})$ compared to other areas. This study provides new constraints on regional-scale tectonic processes such as lithospheric stretching or thinning, due to partial melting beneath the study region that may be an effect of the LAB topography in this part of northern Central Africa.

\section{Introduction}

Mapping and understanding the depth and physical properties of the lithosphere-asthenosphere boundary $(\mathrm{LAB})$ is essential for interpreting processes occurring within the upper mantle structure, the tectonics of lithospheric plates, and the evolution of the Earth (McKenzie and Priestley, 2008; Liu and Gao, 2018). In addition, the variations in the depth of the LAB within cratons and extensional provinces can provide further details about the mechanisms driving the behavior of tectonic plates (e.g., Abt et al., 2010). The base of the lithosphere, i.e., the LAB, and the mid-lithospheric discontinuity (MLD) have been detected in different regions using negative velocity contrasts (e.g., Fischer et al., 2010; Liu and Gao, 2018; Wirth and Long, 2014).

The lithosphere of North Africa has a rich tectonic history that includes Pan-African orogenesis, volcanism, subduction, and present-day extension in the Sirte Basin (e.g., Lemnifi et al., 2015; 2017; 2019) (Figure 1). Numerous global and regional tomographic studies (e.g., Marone et al., 2003; Li'egeois et al., 2005; Pasyanos and Nyblade, 2007; Montagner et al., 2007; Fishwick, 2010; Bardintzeff et al., 2012) have shown weak velocity anomalies, but the depths of their investigations were limited. Volcanic provinces throughout northern Central Africa (Figure 1) are mainly associated with negative Bouguer anomalies, and the lithospheric thickness indicated from surface wave tomography is relatively thin, approximately 90 to $100 \mathrm{~km}$ (Fishwick, 2010). 
To investigate the lithospheric thickness and discontinuities within the lithosphere, two essential seismological techniques are used: surface wave tomography (McKenzie and Priestley, 2008; Bedle and

Van Der Lee, 2009; Schaeffer and Lebedev, 2014; Caló et al., 2016; Liu and Gao 2018) and receiver function (RF) stacking (Rychert and Shearer, 2009; Fischer et al., 2010; Kind et al., 2012; Liu and Gao, 2018). The most common technique employed to image the Moho is the P-to-S RF method (Zhu and Kanamori, 2000; Gao and Liu, 2014; Liu et al., 2017; Lemnifi et al., 2019). This method has disadvantages in imaging the LAB; for example, strong Moho multiples appear within the expected time window of the arrivals associated with the discontinuities of interest (Faber and Müller, 1980; Liu and Gao, 2018). However, the most important benefit of SRFs is that they are less affected by crustal reverberations, which tend to obscure the LAB (e.g., Eaton et al., 2009).

A number of studies have been performed using the SRF method (for a recent summary, see Kind et al., 2012; Liu and Gao, 2018) to determine the LAB. For example, a sharp negative-wave speed discontinuity (NVD) was observed in the depth range of 40-180 km; this NVD, which is regarded as an MLD or the LAB, was previously studied by Fishwick (2010) using a global velocity model. In recent decades, seismicity studies of northern Central Africa have mainly used global surface tomography models, revealing that the lithospheric thickness beneath Central Africa ranges from $90 \mathrm{~km}$ to $100 \mathrm{~km}$, especially beneath volcanic provinces. Lemnifi et al. (2017) suggested that the thinning of the lithosphere may be due to the presence of partial melt and currently active magma reservoirs, which were detected by observing low Vp/Vs ratios obtained through H-k stacking.

Here we use all available seismic data within the study region to investigate the LAB depth therein. For this purpose, we utilize all the recorded data from broadband seismic stations belonging to the Libyan Center for Remote Sensing and Space Science (LCRSSS) and stations that are publicly available and archived by the Incorporated Research Institutions for Seismology (IRIS) Data Management Center 
71 (DMC) to image the depth of the LAB and stacking amplitude associated with lithospheric discontinuities

72 (relative to the direct S wave) beneath northern Central Africa.

\section{2. Method}

74

75

76

77

78

79

80

81

82

83

84

85

86

87

88

89

90

91

The data used in this study were requested from the LCRSSS with a recording period ranging from early 2005 to late 2010. Additionally, we requested data recorded by 3 public broadband seismic stations located in the region between the latitudes of $25^{\circ} \mathrm{N}$ and $36^{\circ} \mathrm{N}$ and the longitudes of $4^{\circ} \mathrm{E}$ and $25^{\circ} \mathrm{E}$ from the IRIS DMC.

\subsection{Receiver function stacking}

Seismic events with epicentral distances ranging from $60^{\circ}$ to $85^{\circ}$ were selected based on a varying cut-off magnitude, which was determined by the epicentral distance and focal depth, as defined by Yuan et al. (2006) and Liu and Gao (2010). The seismograms were windowed starting $180 \mathrm{~s}$ prior to and extending to $20 \mathrm{~s}$ after the first theoretical S-wave arrival according to the IASP91 Earth model. After being bandpass filtered within the frequency band from 0.04 to $0.40 \mathrm{~Hz}$, all of the events that demonstrate a signal-to-noise ratio $(\mathrm{S} / \mathrm{N})$ of 1.5 or greater on the radial component were selected. The cutoff magnitude was determined by the epicentral distance and focal depth as defined by Liu and Gao (2010) using the following equation:

$$
\mathrm{Mc}=5.2+(\mathrm{De}-30.0) /(180.0-30.0)-\mathrm{Hf} / 700
$$

where De is the epicentral distance between $60^{\circ}$ and $85^{\circ}$, for this study, and $\mathrm{Hf}$ is the focal depth in $\mathrm{km}$. To isolate converted $\mathrm{Sp}$ waves from direct $\mathrm{S}$ waves, the ZRT components are rotated into an LQT (P, Sv, $\mathrm{Sh}$ ) ray-based coordinate system, in which the L component is in the direction of the incident $\mathrm{S}$ wave, the $\mathrm{Q}$ component is perpendicular to the $\mathrm{L}$ component and is positive away from the source, and the $\mathrm{T}$ 
92

93

94

95

96

97

98

99

100

101

102

103

104

105

106

107

108

109

110

111

112

component is the third component of the LQT right-hand system. In order to eliminate the influences of the source and ray path, an equalization procedure is applied by deconvolving the $\mathrm{L}$ and $\mathrm{T}$ component seismograms with the $\mathrm{S}$ signal on the Q component. The resulting $\mathrm{L}$ component data are known as $\mathrm{Sp}$ receiver functions, which are mainly composed of the S-to-P converted energy and contain information on the structure beneath a seismic station. A total of 4,520 SRFs were used in the study area.

We stacked the moveout-corrected RFs within circular bins, each with a radius of $2^{\circ}$, based on the locations of the ray-piercing points at a depth of $150 \mathrm{~km}$ (Dueker and Sheehan, 1997). The IASP91 reference Earth model (Kennett and Engdahl, 1991) was employed to calculate the stacked receiver functions with a non-plane wave-front assumption (Gao and Liu, 2014). The moveout procedure employed to correct and stack the SRFs follows a common conversion point (CCP) approach (Dueker and Sheehan, 1997; Liu and Gao, 2018). The moveout correction was applied to stack the SRFs using the following equation (Sheriff and Geldart, 1982; Dueker and Sheehan, 1997; Liu and Gao, 2018) to remove the influence of the ray parameter on the arrival times.

$T_{s p}-T_{s}=\int_{-h}^{0}\left[\sqrt{\left(V_{s}(z)^{-2}-p^{2}\right.}-\sqrt{V_{p}(z)^{-2}-p^{2}}\right] d z$

where $\mathrm{p}$ is the $\mathrm{S}$-wave ray parameter, $\mathrm{h}$ is the depth of the candidate discontinuity (ranging from 0 to 300 $\mathrm{km})$, and $\mathrm{Vp}(\mathrm{z})$ and $\mathrm{Vs}(\mathrm{z})$ are the P- and S-wave velocities, respectively, at the depth z. Stacked traces determined by fewer than 5 RFs were rejected in this study. To increase the reliability of the results, we manually picked the maximum amplitude near the theoretical arrival of the converted $\mathrm{P}$ waves from the LAB.

\section{Results}


The SRFs in the study area produced 156 bins with observable arrivals from the LAB (see Table

1141 for all measurements). The depths of the NVD and the corresponding stacking amplitudes are shown in 115 Table 1 . All the stacked traces plotted along eight latitudes from $21^{\circ} \mathrm{N}$ to $34^{\circ} \mathrm{N}$ are shown in Figures 4 and 1165 and Figures S1 and S2. The observed depth of the LAB increases systematically toward the northern 117 central study area from approximately $70 \mathrm{~km}$ to $120 \mathrm{~km}$ (Figure 4). The apparent depth of the LAB 118 increases from 70 to $90 \mathrm{~km}$ from latitudes $21^{\circ}$ to $28^{\circ}$ and then increases to $124 \mathrm{~km}$ from latitudes $28^{\circ}$ to $11934^{\circ}$. The changes in the LAB depth are extreme beneath the northern central part of Libya (Figures 5 and 120 6). The depths of the LAB beneath the Hoggar volcanic province are relatively shallow compared with 121 those in other areas, while the LAB depth increases beneath the northeastern portion of Libya. The 122 resulting LAB depths in the southern part of the study region are shallow compared to those in the northern 123 part of the study area; in other words, the LAB is especially shallow beneath the Hoggar volcanic province 124 and the western margin of the Tibesti volcanic province. The LAB depth is slightly shallower than normal 125 beneath the northeastern part of the region, as well as beneath the northwestern part of the study area, 126 where the LAB depth ranges from 74 to $96 \mathrm{~km}$ with an average of $83 \pm 5 \mathrm{~km}$.

\section{Discussion}

The depth of the LAB beneath the study area appears to vary widely by a few tens of kilometers (Figures 5, 6, and 7). Parts of the study area, such as the Hoggar and Tibesti volcanic provinces, are characterized by a shallow discontinuity. The LAB was determined according to a significant negative

132 velocity contrast. Some previous studies (e.g., Faul and Jackson, 2005; Stixrude and Lithgow-Bertelloni, 133 2005; Priestley and McKenzie, 2006; Abt et al., 2010) interpreted that the velocity is reduced from the 134 lithosphere to the asthenosphere due to a temperature difference or a combination of temperature and grain 135 size. In contrast, Lee (2003), Schutt and Lesher (2006) concluded that the decrease in the shear-wave 
velocity can be attributed to partial melting. Comparing our results with some geodynamic prediction models (e.g., King and Ritsema, 2000; Korenaga and Jordan, 2002; Cooper et al., 2004) and the lithospheric layering model beneath the United States constrained by Liu and Gao (2018), who also used S-to-P receiver functions, the presence of varying velocities (Figures 5 and 6 ) likely indicates that the asthenosphere contains partial melt with a small amount of hydration relative to the lithospheric mantle. The larger amplitudes observed in Figures 5 and 6 could also be due to lower asthenospheric velocities. These larger amplitudes were similarly observed elsewhere, such as in the Vs model by Yuan and Romanowicz (2010), suggesting that the larger amplitude of the negative velocity contrast beneath the western United States is due to high temperatures, partial melt beneath the lithosphere, and a melt-free lithosphere. In addition, some other studies, such as that conducted by Anderson and Sammis (1970), suggested that the reduction in the seismic velocity may be caused by partial melting, which is consistent with our observation.

More recently, by using receiver function analysis, Lemnifi et al. (2019) found that the MTZ beneath the volcanic provinces in the study area is approximately $10 \mathrm{~km}$ thinner than normal. The average lithospheric thickness beneath the Hoggar volcanic province is $\sim 10 \mathrm{~km}$ less than the normal thickness of $75 \mathrm{~km}$, which is consistent with the elevation and Bouguer gravity anomalies (e.g., Parsons et al., 1994; Liu and Gao, 2010). The average LAB depths beneath the volcanic provinces throughout Libya, such as the Al Haruj, As Sawda, and Tibesti volcanic provinces, relative to the LAB depth beneath the Hoggar volcanic province suggest that the lithosphere beneath the Hoggar volcanic province is older that that beneath the others and has thus been subjected to more extension and thermal erosion. Therefore, we conclude that a possible mechanism contributing to the shallowing of the LAB is stretching of the lithosphere, which is caused by partial melting and the upwelling of hot materials from deep sources. In addition, Abdelsalam et al. (2002) and Lemnifi et al. (2015 and 2017) reported that the lower part of the 
lithosphere is being removed due to partial melting. In the northwestern and northeastern parts of the study area, the crustal thickness is incomparable. This suggests that the entire lithosphere is being uniformly stretched. Generally, the Hoggar and Tibesti volcanic provinces, which are characterized by negative Bouguer anomalies (Figure 1), are being uplifted in conjunction with lithospheric thinning. The S-wave velocity anomaly images by Abdelslam et al. (2011) show negative shear-wave velocities at depths of 100-175 km, suggesting that these anomalies are related to the delamination of a cratonic root.

A shallow NVD depth was observed beneath the Hoggar and Tibesti volcanic provinces with a mean of $73 \pm 10 \mathrm{~km}$ (Table 1), which is comparable to the depths beneath the other regions, including the central part of Libya. In the areas adjacent to volcanic provinces, especially beneath the Hoggar volcanic province, the depths of the LAB are the shallowest $(62-70 \mathrm{~km})$ in the entire study area, and the crustal thickness is $35 \mathrm{~km}$ (Liu and Gao, 2010). The thinning of the lithosphere beneath the Hoggar volcanic province and adjacent areas, such as the Tibesti volcanic province, is consistent with the MTZ thinning hypothesis, which probably originates from the upwelling of hot material from deep sources (Lemnifi et al., 2019). The amount of thinning of the lithosphere is probably proportional to the magnitude of stretching or the amount of partial melt. Our finding is not in agreement with the finding of Liégeois et al. (2005), who used global geophysical modeling and suggested that the lithosphere is relatively thick beneath the Hoggar region.

Other areas with a shallow LAB $(\sim 75 \mathrm{~km})$ are the central part of Libya, namely, the Al Haruj and As Sawda volcanic provinces, and the northwestern part of Libya, which is characterized by a crustal thickness of approximately 30 to $35 \mathrm{~km}$ (Lemnifi et al., 2017). Marone et al. (2003), Li'egeois et al. (2005), Pasyanos and Nyblade (2007), Montagner et al. (2007), Fishwick (2010), and Bardintzeff et al. (2012) observed negative velocity anomalies beneath the same volcanic provinces from global velocity models. For example, low-velocity zones were noted near depths of $90 \mathrm{~km}$ and $107 \mathrm{~km}$ in the central part of the 
Al Haruj volcanic province. They interpreted that these shallow negative velocity anomalies were probably caused by partial melting. Compared with our lithospheric thickness observations beneath northern Central Africa (62-124 km), the amount of thinning of the subcrustal lithosphere in Fishwick (2010) is comparable. Various studies have suggested that the lithosphere beneath ancient continents (cratons) is thick but widely variable (e.g., Jordan 1975; 1978; Hoffman, 1990; Forte and Perry, 2001). The thick lithosphere beneath Libya (Figure 7) may represent part of the Saharan Metacraton, which extends from the Tuareg Shield to the Arabian-Nubian Shield (Abdelsalam et al., 2002; Lemnifi et al., 2015).

In general, the areas with thin lithosphere have large stacking amplitudes and vice versa (Figure 8). This may suggest that the relationship is attributable to a low degree of partial melting in the topmost layer of the asthenosphere. This is different from other areas, such as the Western United States (Liu and Gao, 2018), which are characterized by a higher degree of partial melting beneath the lithosphere. Here, the degree to which the NVD depths and stacking amplitudes are comparable may reflect a lower degree of partial melting in the topmost asthenosphere and lowermost lithosphere. This may be due to the distance of the study region from the major plate boundaries to the north (e.g., Courtillot et al., 2003).

\section{Conclusions}

This is the first study to detect the thickness of the lithosphere beneath Central Africa using S-to$\mathrm{P}$ receiver functions (SRFs) recorded by 19 broadband seismic stations. A robust negative-wave speed discontinuity is revealed at depths ranging between $57 \mathrm{~km}$ and $110 \mathrm{~km}$ with a mean of $80 \pm 17 \mathrm{~km}$. However, to better understand the variable thickness of the lithosphere beneath the study region, further investigations should be conducted, and additional seismic stations must be installed. Beneath central Libya, the LAB depth ranges from $67 \mathrm{~km}$ to $124 \mathrm{~km}$. The smallest LAB depth was found beneath the Hoggar volcanic province, ranging from $57 \mathrm{~km}$ to $87 \mathrm{~km}$. One explanation for the observed phenomena is 
lithospheric stretching or thinning, which may be due to basal erosion beneath the study region that may

be an effect of the LAB topography beneath this part of northern Central Africa.

207

208

209

210

211

212

213

214

215

216

217

218

219

220

221

222

223

224

225

226

227

228

229

230

231

232

233

\section{Acknowledgments}

We thank the participants of the Libyan National Seismological Network (LNSN) and the Incorporated Research Institutions for Seismology (IRIS) Data Management Center (DMC) for providing the highquality seismic data used in the study.

\section{References}

Abdelsalam, M. G., Liégeois, J. P., Stern, R. J., 2002. The Saharan Metacraton. J. Afr. Earth Sci. 34, 119136. https://doi.org/10.1016/S0899-5362(02)00013-1.

Abdelsalam, M.G., Gao, S.S., Ligeois, J.P., 2011. Upper mantle structure of the Saharan Metacraton. J. Afr. Earth Sci. 60, 328-336. https://doi.org/10.1016/j.jafrearsci. 2011.03.009.

Abt, D. L., Fischer, K. M., French, S. W., Ford, H. A., Yuan, H., Romanowicz, B., 2010. NorthAmerican lithospheric discontinuity structure imaged by Ps and Sp receiverfunctions. J. Geophys. Res. 115, B09301.doi:10.1029/2009JB006914.

Anderson, D.L., Spetzler, H., 1970. Partial melting and the low-velocity zone. Phys.Earth Planet. Inter. 4, $62-64$.

Bardintzeff, J. M., Deniel, C., Guillou, H., Platevoet, B., T'clouk, P., Oun, K. H., 2012. Miocene to recent alkaline volcanism between Al Haruj and Waw an Namous (southern Libya). J. Inter. Earth Sci. 101, 1047-1063.

Bedle, H., Van Der Lee, S., 2009. S velocity variations beneath North America. J. Geophys. Res. 114(B7).https://doi.org/10.1029/2008JB005949https://doi.org/10.1007/s00531-011-

Caló, M., Bodin, T., Romanowicz, B., 2016. Layered structure in the upper mantle across North America from joint inversion of long and short period seismic data. Earth Planet. Sci. Lett. 499,164175.https://doi.org/10.1016/j.eps1.2016.05.0540708-5

Cooper, C.M., Lenardic, A., Moresi, L., 2004. The thermal structure of stable continental lithosphere within a dynamic mantle. Earth Planet. Sci. Lett. 222, 807-817

Courtillot, V., Davaille, A., Besse, J., Stock, J., 2003. Three distinct types of hotspots in the Earth's mantle. Earth Planet. Sci. Lett. 205, 295-308. https://doi.org/10.1016/S0012-821X(02)01048-8 
Dueker, K. G., Sheehan, A. F., 1997. Mantle discontinuity structure from midpoint stacks of converted P to S waves across the Yellowstone hotspot track. J. Geophys. Res.: Solid Earth, 102(B4), 83138327.

Eaton, D. W., Darbyshire, F., Evans, R. L., Grutter, H., Jones, A. G., Yuan, X., 2009. The elusive lithosphere - asthenosphere boundary beneath cratons, Lithos, 109,1

Faber, S., Müller, G., 1980. Sp phases from the transition zone between the upper and lower mantle. Bull. Seismol. Soc. Am. 70 (2), 487-508.

Faul, U. H., Jackson, I., 2005. The seismological signature of temperature and grain size variations in the upper mantle. Earth Planet. Sci. Lett. 234, 119-134.

Fischer, K. M., Ford, H. A., Abt, D. L., Rychert, C. A., 2010. The lithosphere-asthenosphere boundary. Annu. Rev. Earth Planet. Sci., 38, 551-575, doi:10.1146/annurev-earth-040809-152438.

Fishwick, S., 2010. Surface wave tomography: Imaging of the lithosphere asthenosphere boundary beneath central and southern Africa? Lithos,120(1),63-73. https://doi.org/10.1016/j.lithos.2010.05.011

Gao, S. S., Liu, K. H., 2014. Mantle transition zone discontinuities beneath the contiguous United States. J. Geophys. Res.: Solid Earth, 119(8), 6452-6468.

Kennett, B. L. N., Engdahl, E. R., 1991. Traveltimes for global earthquake location and phase identification: J. Geophys. Inter. 105, 429-465, doi: 10 .1111/j.1365 -246X.1991.tb06724 .x.

Kind, R., Yuan, X., Kumar, P., 2012. Seismic receiver functions and the lithosphere-asthenosphere boundary. Tectonophysics 536, 25-43. https://doi.org/10.1016/j.tecto.2012.03.005.

King, S.D., Ritsema, J., 2000. African hot spot volcanism: small-scale convection in the upper mantle beneath cratons. Science 290, 1137-1140.

Korenaga, J., Jordan, T.H., 2002. On the state of sublithospheric upper mantle beneath a supercontinent. J. Geophys. Int. 149, 179-189.

Lee, C. T. A., 2003. Compositional variation of density and seismic velocities in naturalperidotites at STP conditions: implications for seismic imaging of compositional heterogeneities in the upper mantle. J. Geophys. Res. 108. doi:10.1029/2003JB002413.

Lemnifi, A.A., Liu, K.H., Gao, S.S., Reed, C.A., Elsheikh, A.A., Yu, Y., Elmelade, A.A., 2015. Azimuthal anisotropy beneath north central Africa from shear wave splitting analyses. Geochem. Geophys. Geosyst. 16. https://doi.org/10.1002/2014GC005706.

Lemnifi, A., Elshaafi, A., Browning, J., Aouad, N., El Ebadi, S., Liu, K., Gudmundsson, A., 2017. Crustal thickness beneath Libya and the origin of partial melt beneath AS Sawda Volcanic Province from receiver- function constraints. J. Geophys. Res. Solid Earth. https://doi.org/10.1002/2017JB014291. 
Lemnifi, A., Browning, A., Elshaafi, A., Aouad, N., Yu, Y., 2019. Receiver function imaging of mantle transition zone discontinuities and the origin of volcanism beneath Libya. J. Geodynamics, 93103. https://doi.org/10.1016/j.jog.2019.01.009.

Liégeois, J. P., Benhallou, A., Azzouni-Sekkal, A., Yahiaoui, R., Bonin, B., 2005. The Hoggar swell and volcanism: Reactivation of the Precambrian Tuareg shield during Alpine convergence and West African Cenozoic volcanism. Geolog. Soci. Amer., Special Papers,388,379400.https://doi.org/10.1130/0-8137-2388-4.379.

Liu, K. H., Gao, S. S., 2010. Spatial variations of crustal characteristics beneath the Hoggar swell, Algeria, revealed by systematic analyses of receiver functions from a single seismic station. Geochem. Geophys. Geosyst. 11(8). http://doi.org/10.1029/2010GC003091

Liu, L., Gao, S. S., Liu, K. H., Mickus, K., 2017. Receiver function and gravity constraints on crustal structure and vertical movements of the Upper Mississippi Embayment and Ozark Uplift. J. Geophys. Res. 122,4572-4583.https://doi.org/10.1002/2017JB014201

Liu, L., Gao, S., 2018. Lithospheric layering beneath the contiguous United States constrained by S-to-P receiver functions. Earth Planet. Sci. Lett. 495, 79-86.

Marone, F., Van Der Meijde, M., Van Der Lee, S., Giardini, D., 2003. Joint inversion of local, regional and teleseismic data for crustal thickness in the Eurasia-Africa plate boundary region. J. Geophys. Intern. 154 (2), 499-514. https://doi.org/10.1046/j. 1365-246X.2003.01973.x.

McKenzie, D., Priestley, K., 2008. The influence of lithospheric thickness variations on continental evolution. Lithos 102(1),1-11.https://doi.org/10.1016/j.lithos.2007.05.005

Montagner, J.-P., et al., 2007. Mantle upwellings and convective instabilities revealed by seismic tomography and helium isotope geochemistry beneath eastern Africa. Geophys. Res. Lett. https://doi.org/10.10129/2007GL031098. L21303.

Parsons, T., Thompson, G. A., Sleep, N. H., 1994. Mantle plume influence on the Neogene uplift and extension of the US western Cordillera? Geology 22, 83-86.

Pasyanos, M. E., Nyblade, A. A., 2007. A top to bottom lithospheric study of Africa and Arabia. Tectonophysics, 444, 27-44. https://doi.org/10.1016/j.tecto.2007.07.008.

Priestley, K., McKenzie, D., 2006. The thermal structure of the lithosphere from shear wave velocities. Earth Planet. Sci. Lett., 244, 285-301, doi:10.1016/j.eps1.2006.01.008.

Rychert, C. A., Shearer, P. M., 2009. A global view of the lithosphere-asthenosphere boundary. Science, 324, 495 -498, doi:10.1126/ science. 1169754.

Schaeffer, A. J., Lebedev, S., 2014. Imaging the North American continent using wave form inversion of global and US Array data. Earth Planet. Sci. Lett. 402,26-41. https://doi.org/10.1016/j.eps1.2014.05.014. 
302 Schutt, D. L., Lesher, C. E., 2006. Effects of melt depletion on the density and seismic velocity of garnet 303 and spinel lherzolite, J. Geophys. Res., 111, B05401, doi:10.1029/2003JB002950.

304 Sheriff, R. E., Geldart, L. P., 1982. Exploration Seismology. Vol.1: History, Theory, and Data Acquisition. $305 \quad$ Cambridge University Press, Cambridge.

306 Stixrude, L., Lithgow-Bertelloni, C., 2005. Mineralogy and elasticity of the oceanic upper mantle: origin 307 of the low-velocity zone. J. Geophys. Res. 110. doi:10.1029/2004JB002965.

308 Yuan, X., Kind, R., Li, X., Wang, R., 2006. The S receiver functions: synthetics and data example. J. $309 \quad$ Geophys. Inter. 165(2), 555-564.

310 Yuan, H., Romanowicz, B., 2010. Lithospheric layering in the North American Craton. Nature 466, 1063$311 \quad 1068$.

312 Zhu, L. P., Kanamori, H., 2000. Moho depth variation in southern California from teleseismic receiver 313 functions, J. Geophys. Res., 105, 2969-2980, doi:10.1029/1999JB900322. 


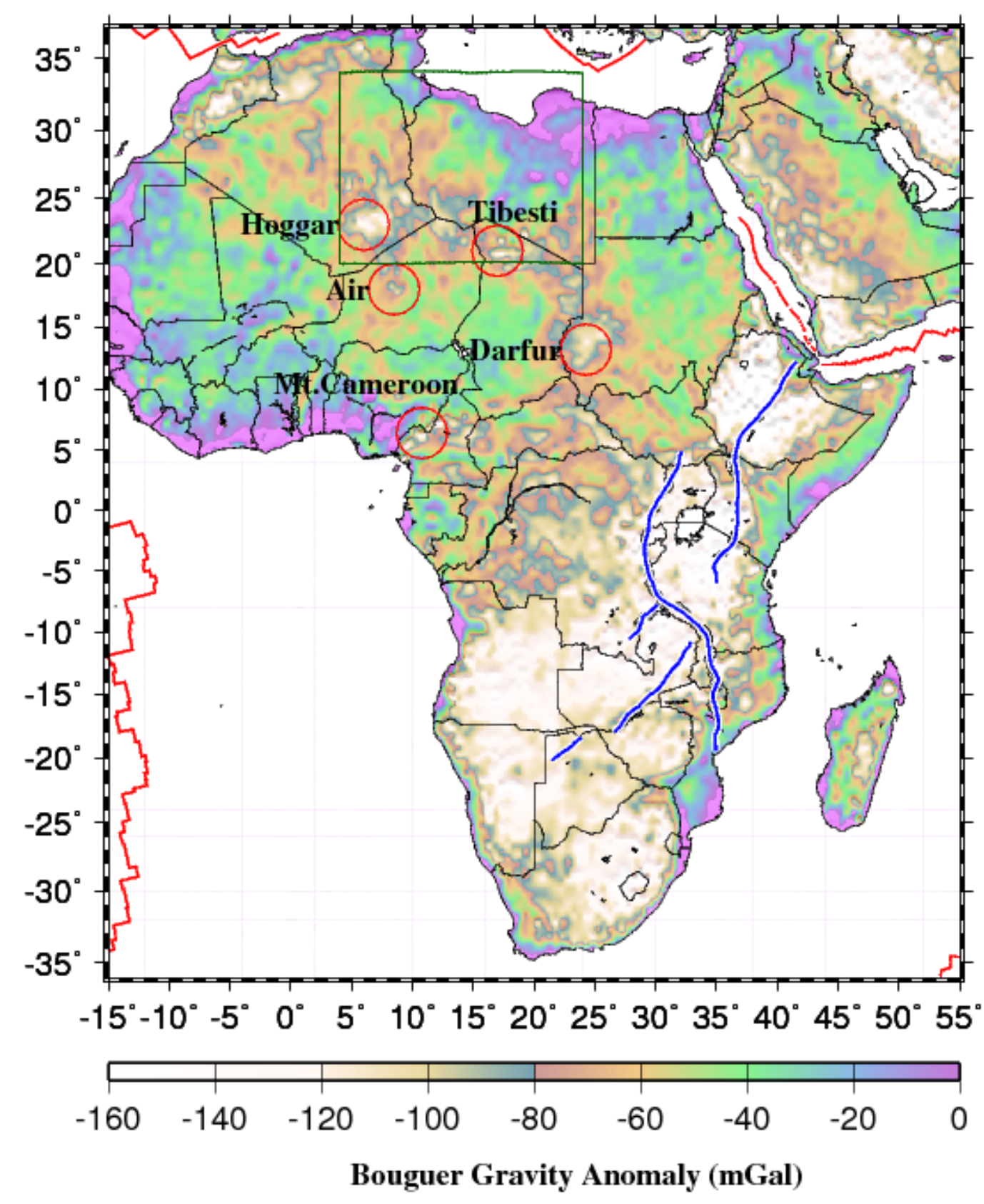

324 Figure 1. Map of the Bouguer gravity anomalies throughout Africa produced using GRACE (Gravity 325 Recovery and Climate Experiment) satellite gravity data (Tapley et al., 2005; Liu and Gao, 2010). The 326 blue lines illustrate the East African Rift System. The green square denote the location of the study area. 327 The circles are centered on the major Cenozoic volcanic provinces of Africa. 


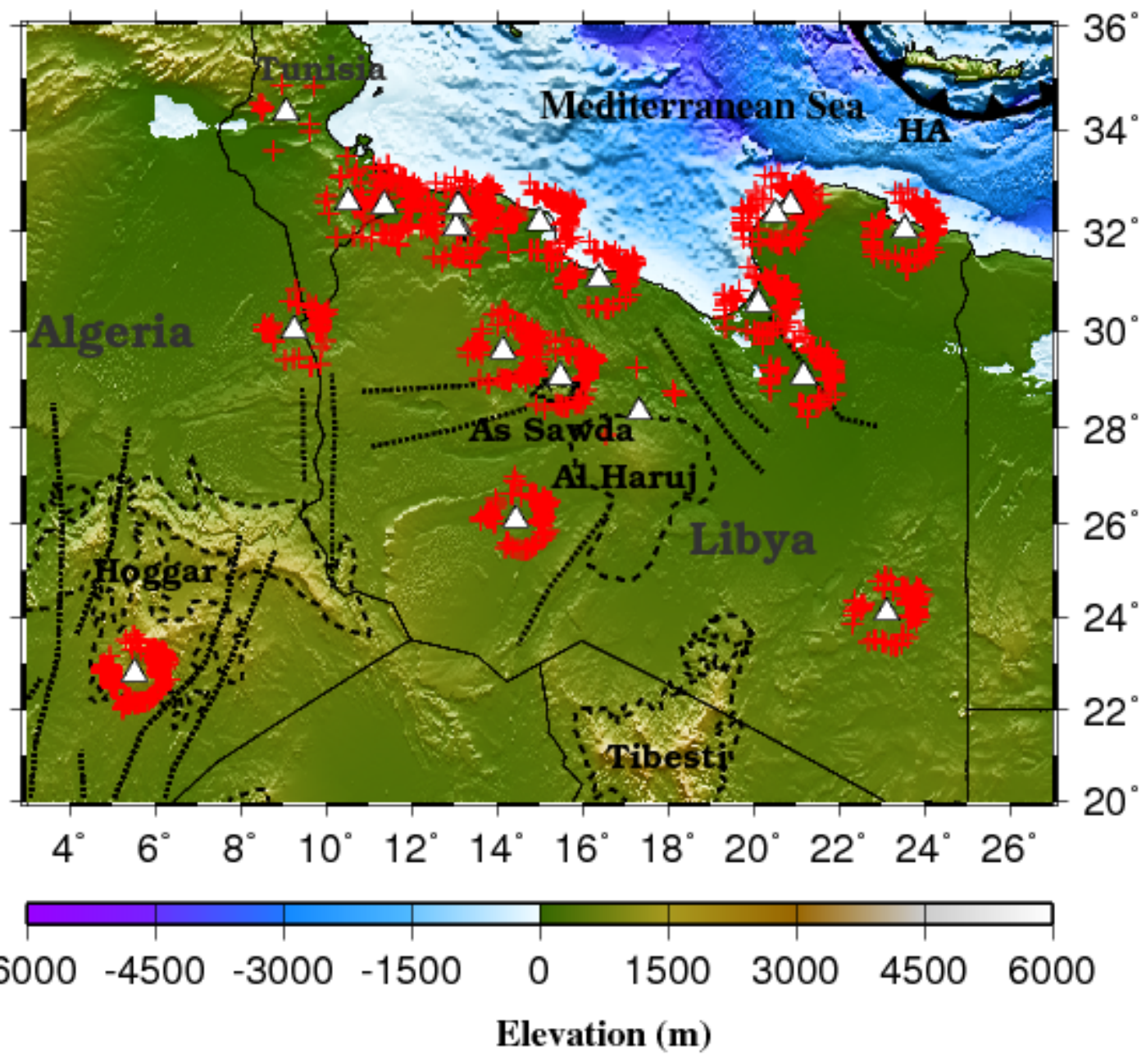

329 Figure 2. Digital elevation map of the study area showing the seismic stations used in the study. Crosses 330 are the ray-piercing points at a depth of $150 \mathrm{~km}$. Black dashed lines surround the major volcanic provinces 331 in the study area. 


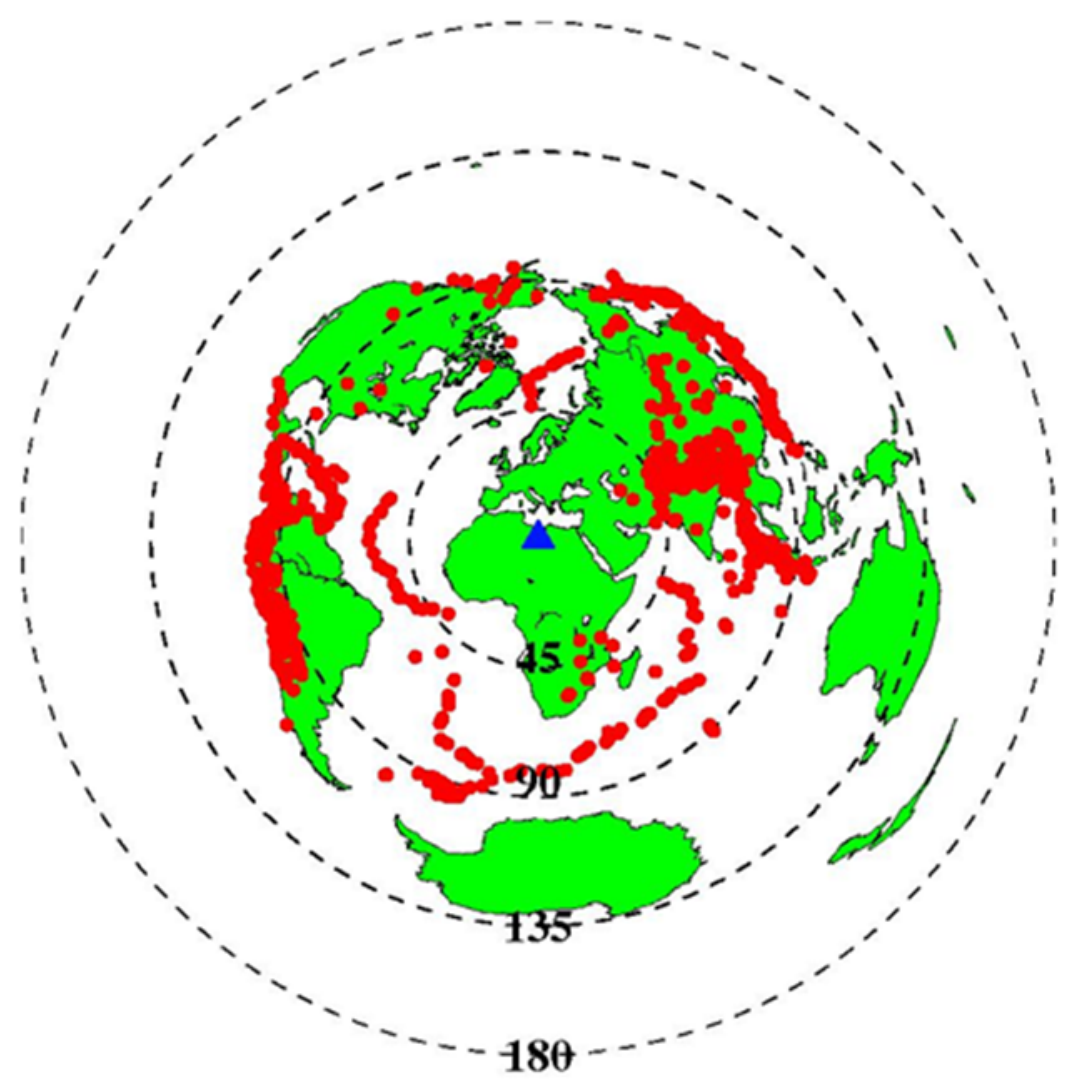

336 Figure 3. An azimuthal equidistant projection map showing the distribution of earthquakes (red dots) used 337 for the receiver function analysis. 


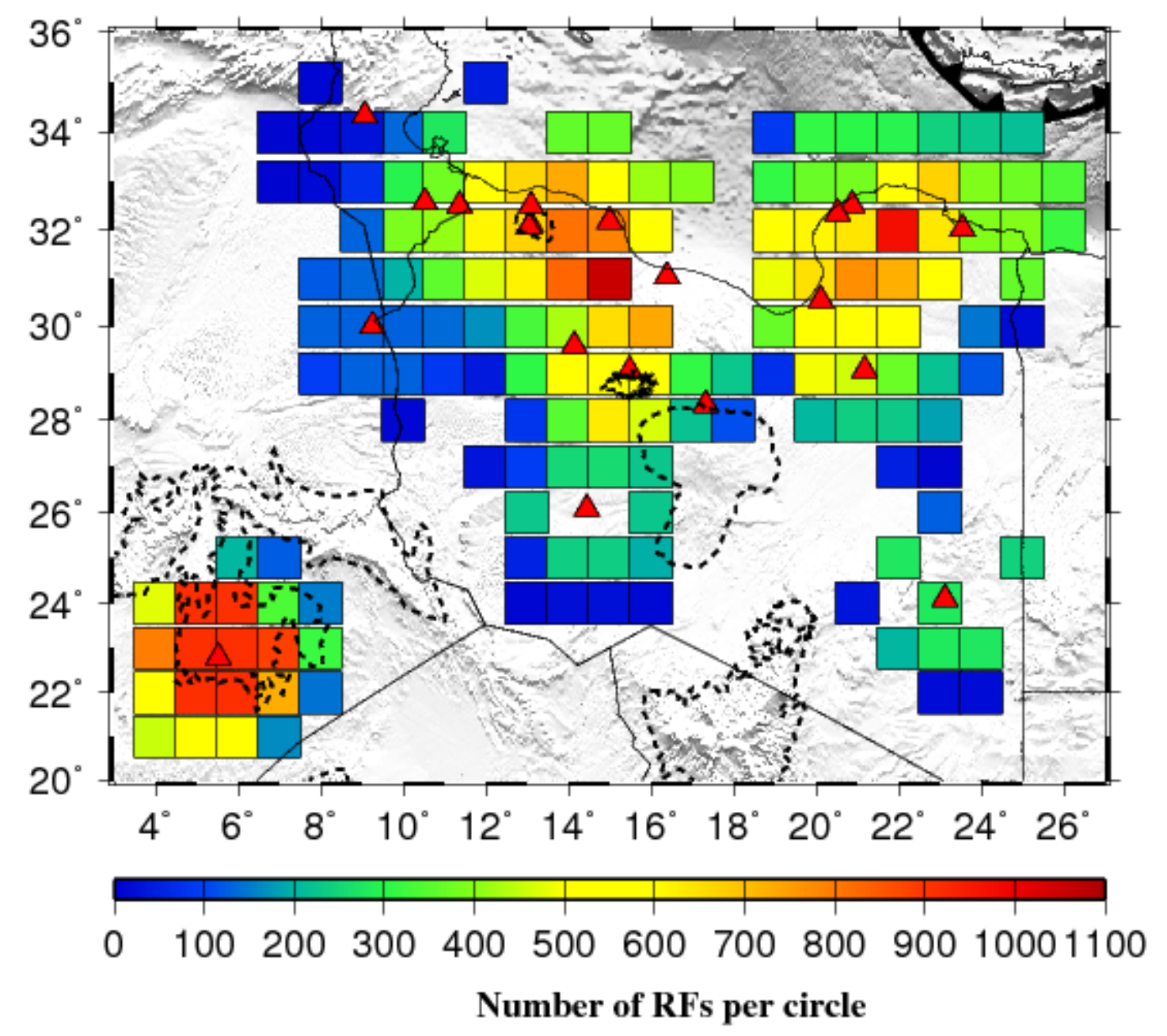

339 Figure 4. Diagram showing the number of RFs in radius=2 degree bins. The color scale represents the 340 number of RFs per bin. 
(a) Latitude $=29^{\circ}$

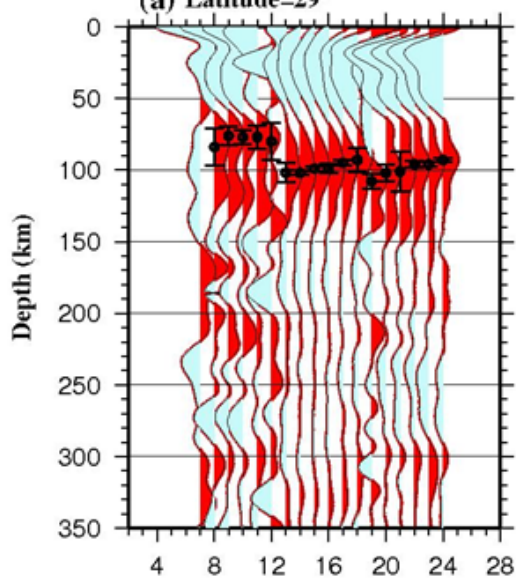

(d) Latitude $=26^{\circ}$
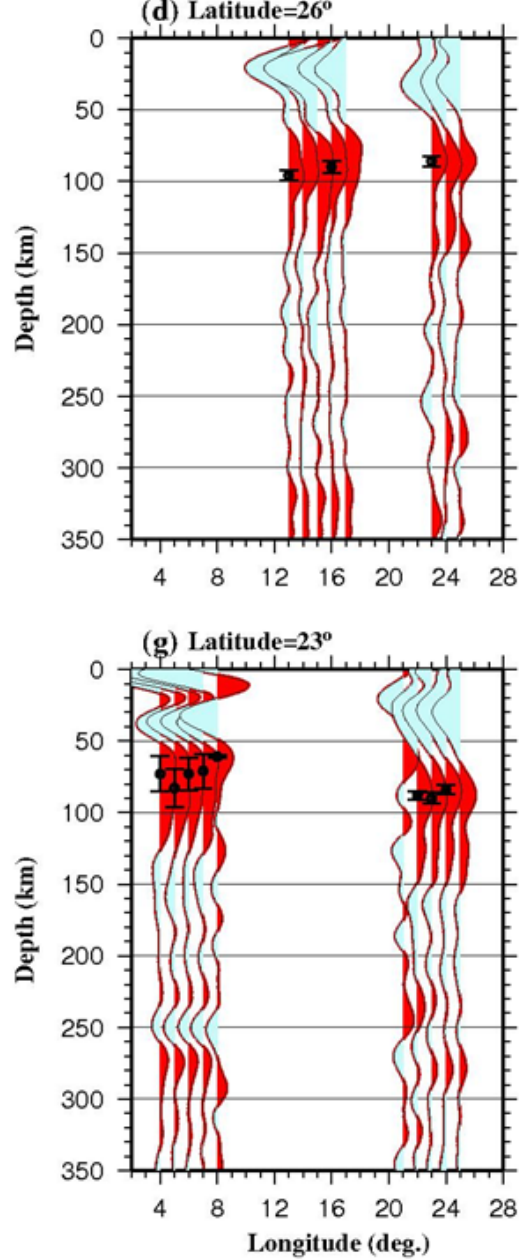

(b) Latitude $=28^{\circ}$

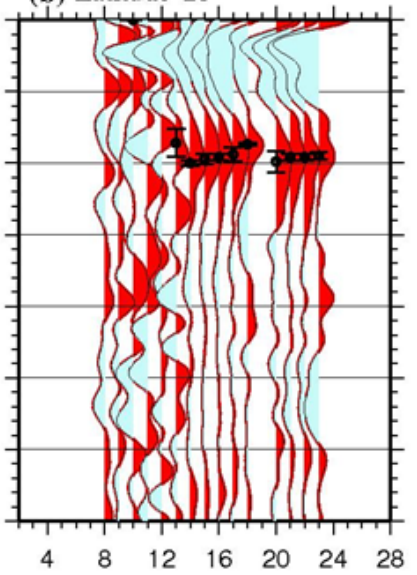

(e) Latitude $=25^{\circ}$

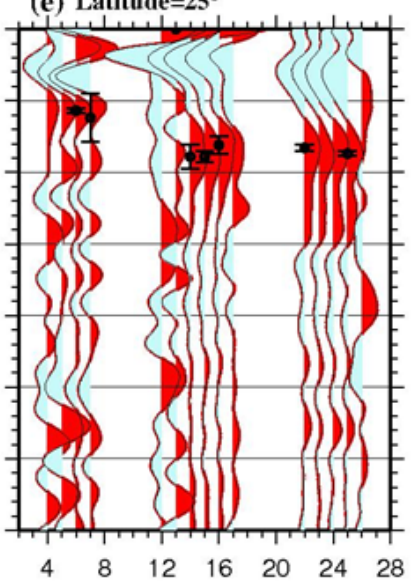

(h) Latitude $=22^{\circ}$

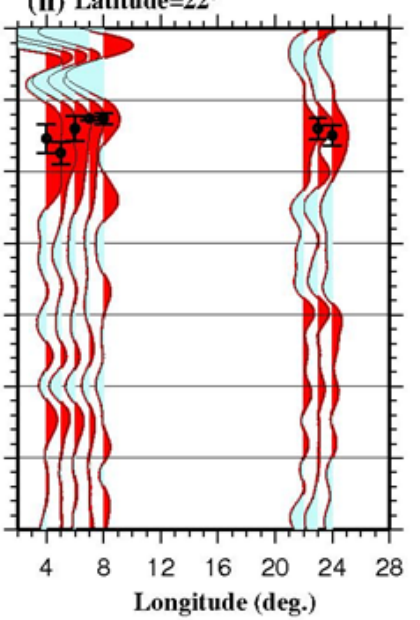

(c) Latitude $=27^{\circ}$

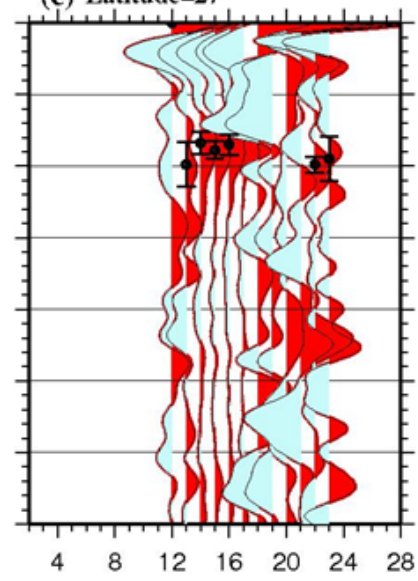

(f) Latitude $=24^{\circ}$

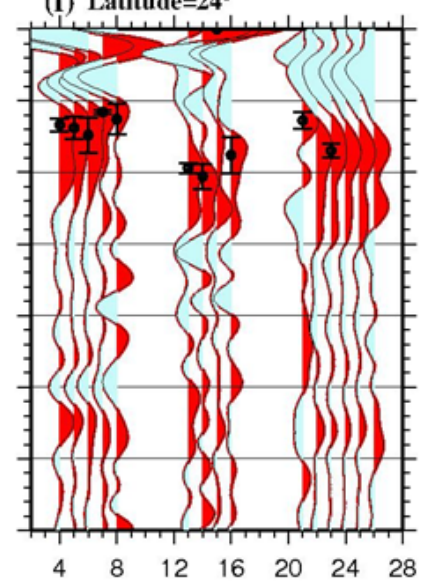

(i) Latitude $=21^{\circ}$

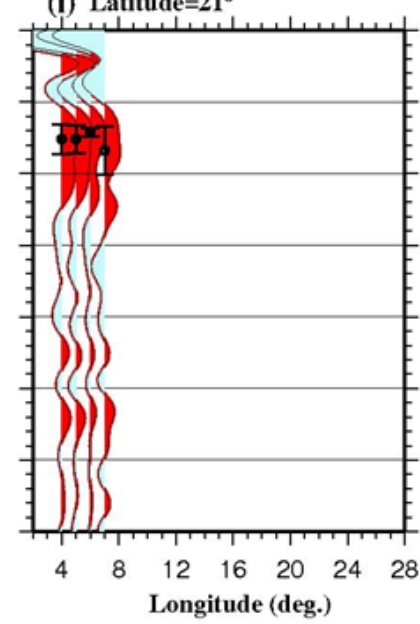

342 Figure 5. E-W stacked S-to-P receiver function profiles showing the depths from 0 to $350 \mathrm{~km}$ at latitudes 343 from $21^{\circ} \mathrm{N}$ to $29^{\circ} \mathrm{N}$. Black circles represent the average depths of the LAB, and black bars show two STDs 344 of the peak depths. 

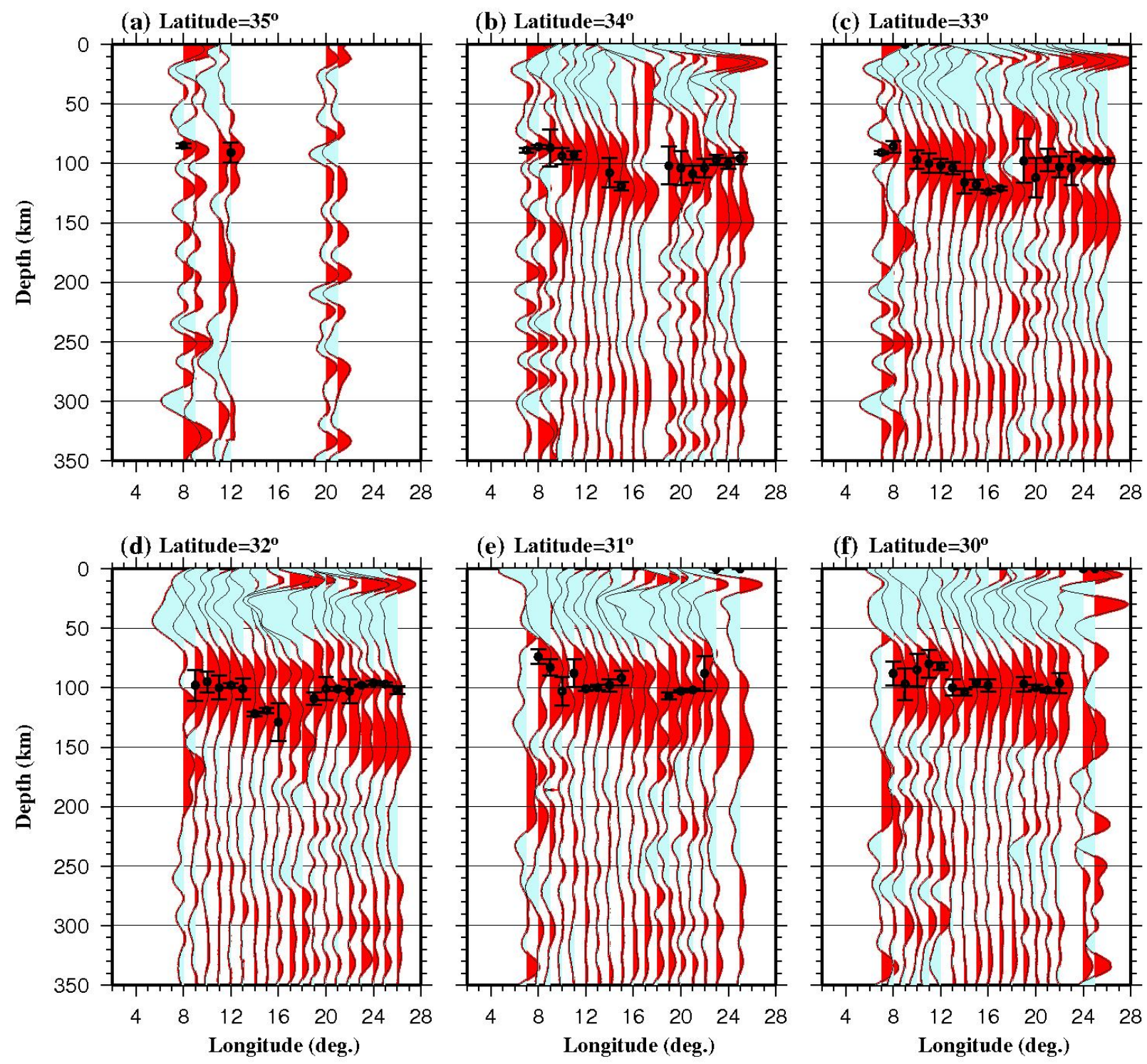

347 Figure 6. Same as Figure 5 but showing the profiles from $30^{\circ} \mathrm{N}$ to $35^{\circ} \mathrm{N}$. Black circles represent the average 348 depths of the LAB, and black bars show two STDs of the peak depths. 


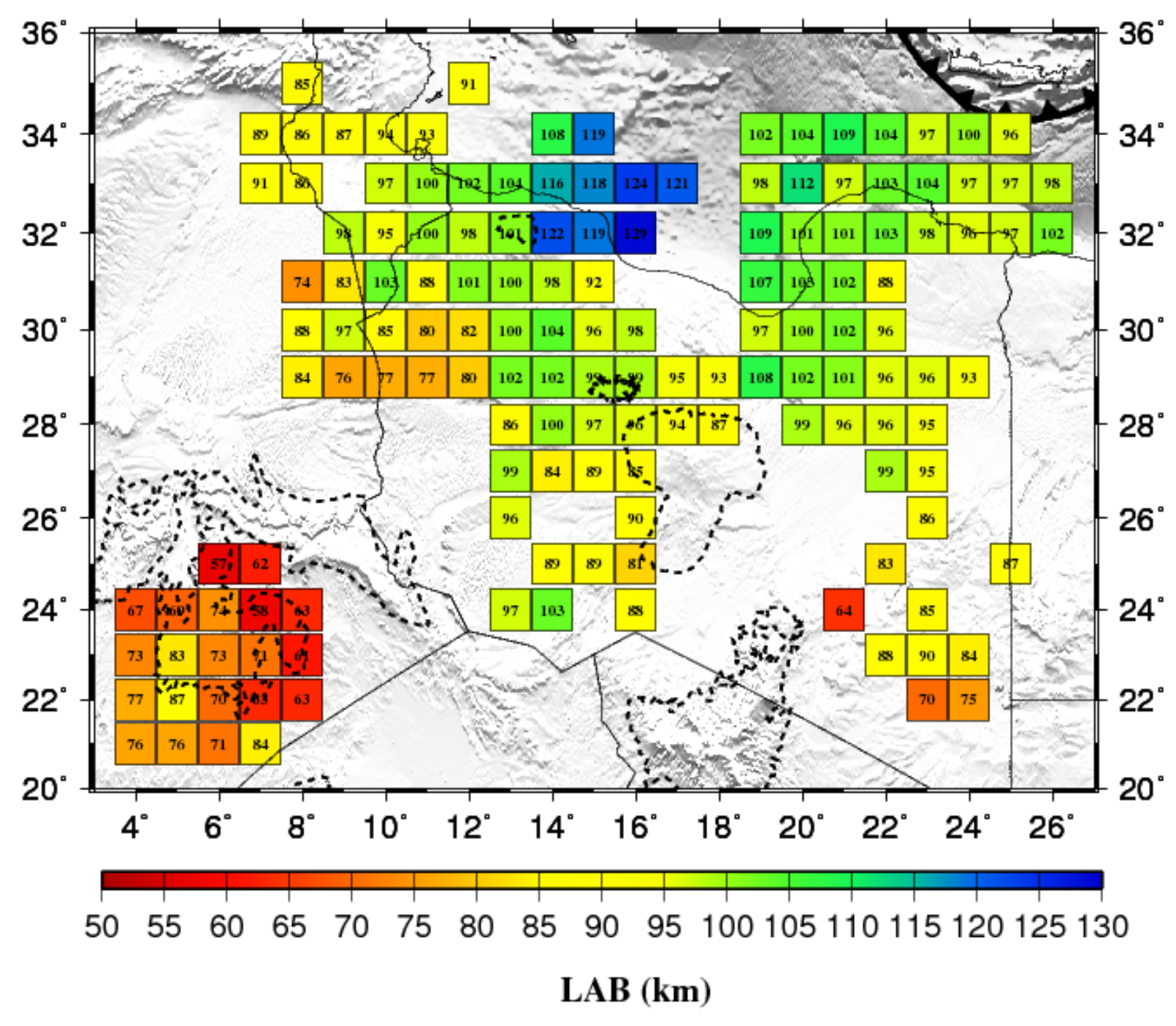

351 Figure 7. Diagram showing the resulting depth of the LAB throughout the study area. The colours 352 represent the $\mathrm{LAB}$ depths from 50 to $130 \mathrm{~km}$, where the mean depth is also given in each locality. 


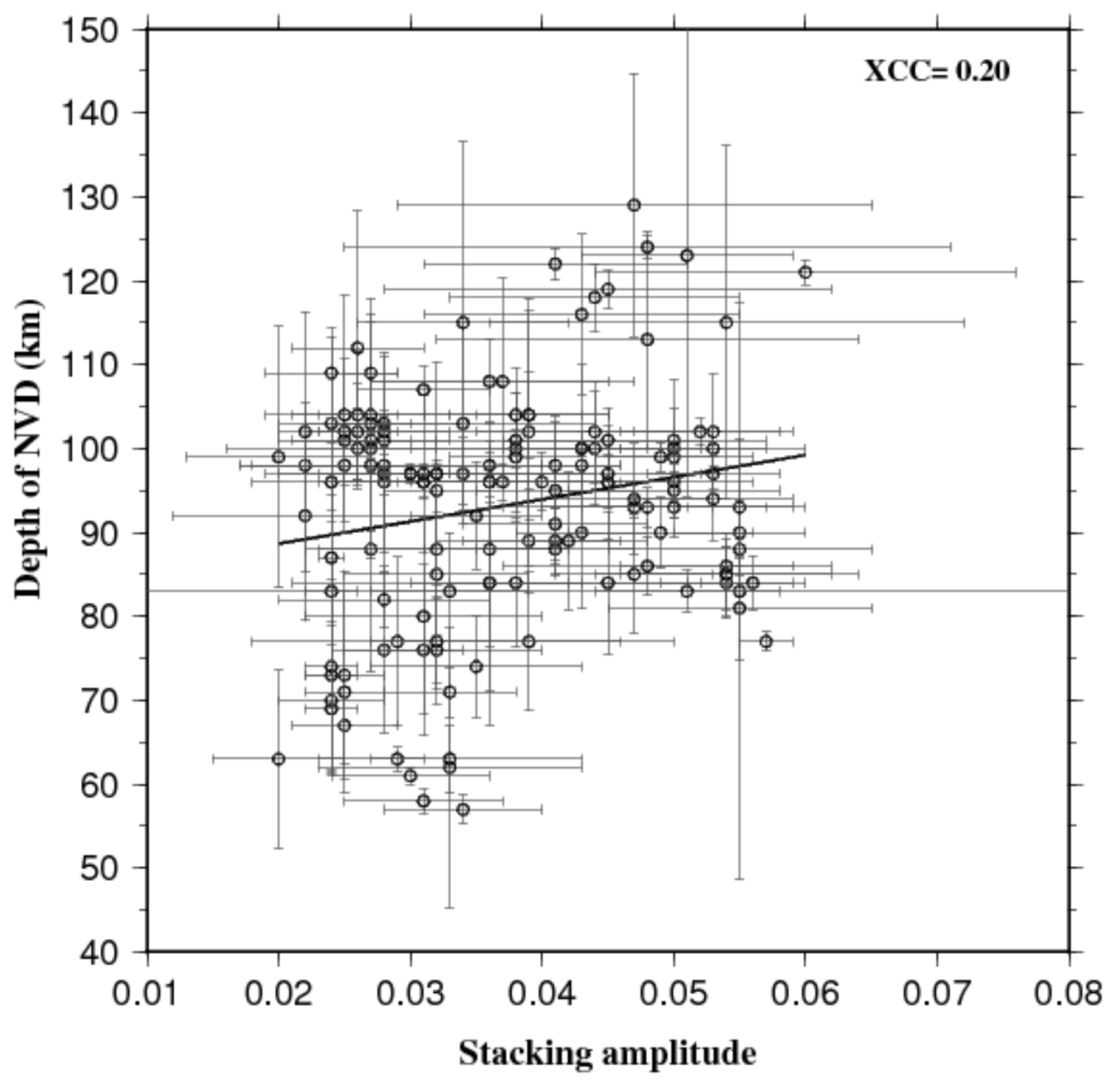

354 Figure 8. Cross-correlation plot of the NVD depths versus the corresponding stacking amplitudes.

355

356

357

358

359 Table. 1. Resulting NVD depths and stacking amplitudes. 


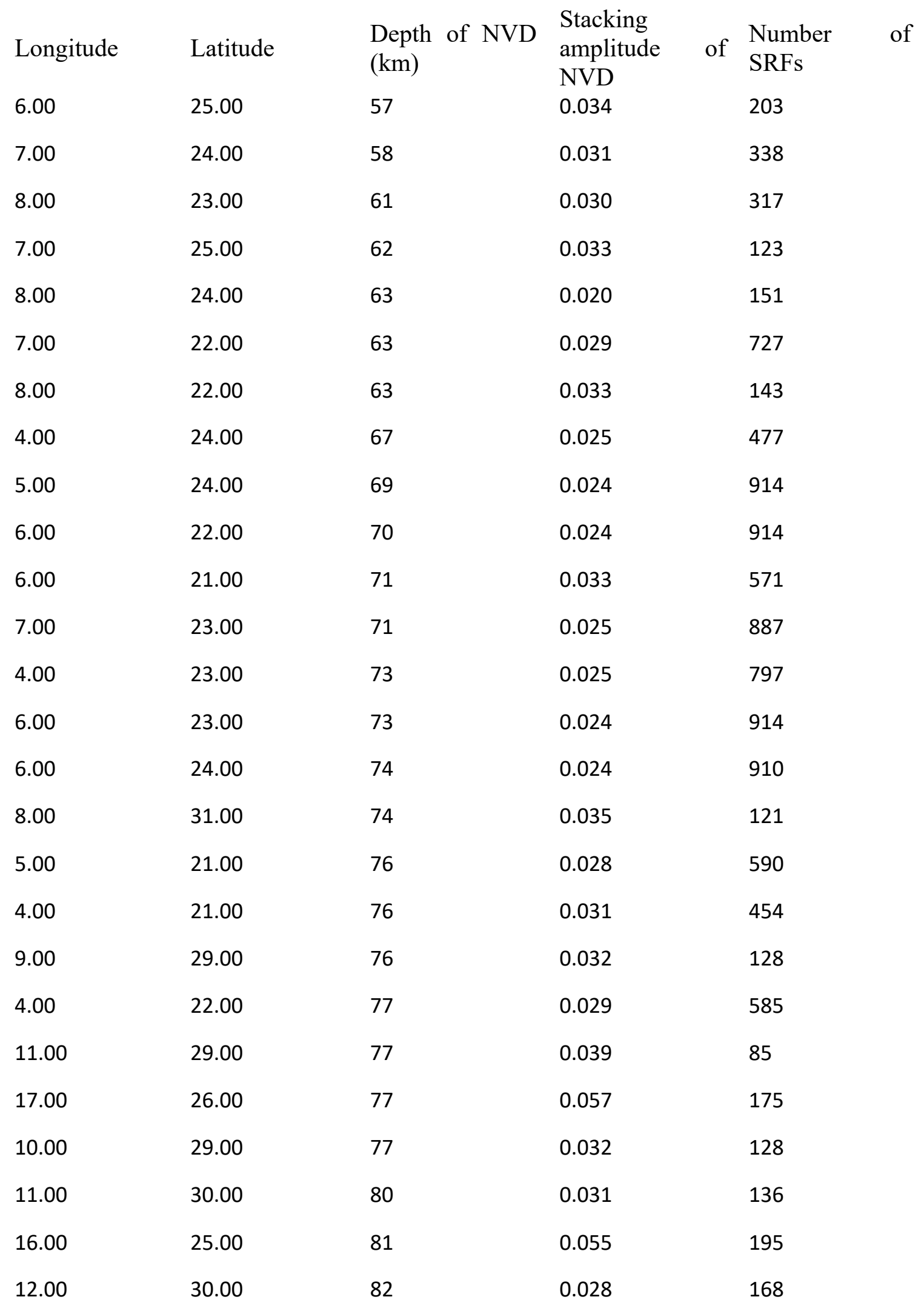




\begin{tabular}{|c|c|c|c|c|}
\hline 5.00 & 23.00 & 83 & 0.024 & 914 \\
\hline 18.00 & 33.00 & 83 & 0.055 & 125 \\
\hline 22.00 & 25.00 & 83 & 0.051 & 275 \\
\hline 9.00 & 31.00 & 83 & 0.033 & 133 \\
\hline 7.00 & 21.00 & 84 & 0.036 & 165 \\
\hline 24.00 & 25.00 & 84 & 0.054 & 279 \\
\hline 24.00 & 23.00 & 84 & 0.056 & 275 \\
\hline 14.00 & 27.00 & 84 & 0.038 & 251 \\
\hline 8.00 & 29.00 & 84 & 0.036 & 94 \\
\hline 17.00 & 27.00 & 84 & 0.045 & 161 \\
\hline 22.00 & 24.00 & 85 & 0.054 & 279 \\
\hline 10.00 & 30.00 & 85 & 0.032 & 128 \\
\hline 23.00 & 24.00 & 85 & 0.054 & 279 \\
\hline 25.00 & 26.00 & 85 & 0.091 & 50 \\
\hline 16.00 & 27.00 & 85 & 0.047 & 226 \\
\hline 24.00 & 24.00 & 86 & 0.054 & 279 \\
\hline 23.00 & 26.00 & 86 & 0.048 & 125 \\
\hline 25.00 & 24.00 & 86 & 0.063 & 253 \\
\hline 5.00 & 22.00 & 87 & 0.024 & 914 \\
\hline 18.00 & 28.00 & 87 & 0.061 & 111 \\
\hline 25.00 & 23.00 & 87 & 0.068 & 232 \\
\hline 25.00 & 25.00 & 87 & 0.065 & 242 \\
\hline 22.00 & 31.00 & 88 & 0.027 & 726 \\
\hline 11.00 & 31.00 & 88 & 0.036 & 356 \\
\hline 8.00 & 30.00 & 88 & 0.032 & 128 \\
\hline 24.00 & 26.00 & 88 & 0.069 & 225 \\
\hline 22.00 & 23.00 & 88 & 0.041 & 203 \\
\hline 23.00 & 25.00 & 88 & 0.055 & \\
\hline
\end{tabular}




\begin{tabular}{|c|c|c|c|c|}
\hline 15.00 & 27.00 & 89 & 0.039 & 256 \\
\hline 15.00 & 25.00 & 89 & 0.041 & 236 \\
\hline 14.00 & 25.00 & 89 & 0.042 & 236 \\
\hline 23.00 & 23.00 & 90 & 0.055 & 279 \\
\hline 15.00 & 26.00 & 90 & 0.043 & 237 \\
\hline 16.00 & 26.00 & 90 & 0.049 & 226 \\
\hline 14.00 & 26.00 & 91 & 0.041 & 238 \\
\hline 15.00 & 31.00 & 92 & 0.035 & 1056 \\
\hline 13.00 & 28.00 & 92 & 0.022 & 81 \\
\hline 24.00 & 29.00 & 93 & 0.047 & 119 \\
\hline 17.00 & 30.00 & 93 & 0.048 & 539 \\
\hline 18.00 & 29.00 & 93 & 0.055 & 227 \\
\hline 11.00 & 34.00 & 93 & 0.050 & 277 \\
\hline 10.00 & 34.00 & 94 & 0.047 & 134 \\
\hline 17.00 & 28.00 & 94 & 0.053 & 220 \\
\hline 10.00 & 32.00 & 95 & 0.041 & 387 \\
\hline 23.00 & 28.00 & 95 & 0.032 & 183 \\
\hline 18.00 & 30.00 & 95 & 0.050 & 392 \\
\hline 17.00 & 29.00 & 95 & 0.061 & 310 \\
\hline 13.00 & 26.00 & 96 & 0.040 & 227 \\
\hline 22.00 & 29.00 & 96 & 0.031 & 369 \\
\hline 22.00 & 30.00 & 96 & 0.028 & 523 \\
\hline 16.00 & 28.00 & 96 & 0.050 & 467 \\
\hline 21.00 & 28.00 & 96 & 0.036 & 238 \\
\hline 22.00 & 28.00 & 96 & 0.037 & 231 \\
\hline 25.00 & 34.00 & 96 & 0.024 & 215 \\
\hline 23.00 & 29.00 & 96 & 0.036 & 220 \\
\hline 15.00 & 30.00 & 96 & 0.045 & 653 \\
\hline
\end{tabular}




\begin{tabular}{|c|c|c|c|c|}
\hline 24.00 & 32.00 & 96 & 0.031 & 393 \\
\hline 23.00 & 34.00 & 97 & 0.034 & 242 \\
\hline 19.00 & 30.00 & 97 & 0.028 & 366 \\
\hline 10.00 & 33.00 & 97 & 0.045 & 294 \\
\hline 24.00 & 33.00 & 97 & 0.032 & 393 \\
\hline 25.00 & 33.00 & 97 & 0.030 & 372 \\
\hline 21.00 & 33.00 & 97 & 0.031 & 381 \\
\hline 25.00 & 32.00 & 97 & 0.030 & 393 \\
\hline 15.00 & 28.00 & 97 & 0.053 & 631 \\
\hline 9.00 & 30.00 & 97 & 0.032 & 128 \\
\hline 19.00 & 33.00 & 98 & 0.022 & 308 \\
\hline 16.00 & 30.00 & 98 & 0.041 & 736 \\
\hline 14.00 & 31.00 & 98 & 0.036 & 832 \\
\hline 26.00 & 33.00 & 98 & 0.025 & 339 \\
\hline 12.00 & 32.00 & 98 & 0.043 & 614 \\
\hline 9.00 & 32.00 & 98 & 0.028 & 129 \\
\hline 23.00 & 32.00 & 98 & 0.027 & 637 \\
\hline 16.00 & 29.00 & 99 & 0.050 & 512 \\
\hline 20.00 & 28.00 & 99 & 0.038 & 204 \\
\hline 15.00 & 29.00 & 99 & 0.049 & 531 \\
\hline 13.00 & 27.00 & 99 & 0.020 & 92 \\
\hline 20.00 & 30.00 & 100 & 0.027 & 542 \\
\hline 11.00 & 33.00 & 100 & 0.050 & 376 \\
\hline 12.00 & 34.00 & 100 & 0.053 & 375 \\
\hline 13.00 & 31.00 & 100 & 0.038 & 620 \\
\hline 14.00 & 28.00 & 100 & 0.043 & 349 \\
\hline 11.00 & 32.00 & 100 & 0.043 & 409 \\
\hline 13.00 & 30.00 & 100 & 0.044 & \\
\hline
\end{tabular}




\begin{tabular}{|c|c|c|c|c|}
\hline 24.00 & 34.00 & 100 & 0.026 & 226 \\
\hline 13.00 & 34.00 & 101 & 0.050 & 440 \\
\hline 21.00 & 29.00 & 101 & 0.027 & 459 \\
\hline 20.00 & 32.00 & 101 & 0.025 & 615 \\
\hline 12.00 & 31.00 & 101 & 0.045 & 469 \\
\hline 13.00 & 32.00 & 101 & 0.038 & 670 \\
\hline 21.00 & 32.00 & 101 & 0.028 & 641 \\
\hline 21.00 & 30.00 & 102 & 0.028 & 550 \\
\hline 19.00 & 34.00 & 102 & 0.039 & 86 \\
\hline 14.00 & 29.00 & 102 & 0.052 & 515 \\
\hline 13.00 & 29.00 & 102 & 0.053 & 305 \\
\hline 21.00 & 31.00 & 102 & 0.025 & 772 \\
\hline 26.00 & 32.00 & 102 & 0.022 & 319 \\
\hline 20.00 & 29.00 & 102 & 0.026 & 491 \\
\hline 12.00 & 33.00 & 102 & 0.044 & 597 \\
\hline 22.00 & 33.00 & 103 & 0.028 & 556 \\
\hline 20.00 & 31.00 & 103 & 0.027 & 649 \\
\hline 22.00 & 32.00 & 103 & 0.024 & 974 \\
\hline 10.00 & 31.00 & 103 & 0.034 & 198 \\
\hline 20.00 & 34.00 & 104 & 0.025 & 309 \\
\hline 16.00 & 31.00 & 104 & 0.039 & 912 \\
\hline 13.00 & 33.00 & 104 & 0.039 & 665 \\
\hline 22.00 & 34.00 & 104 & 0.026 & 295 \\
\hline 14.00 & 30.00 & 104 & 0.038 & 429 \\
\hline 23.00 & 33.00 & 104 & 0.027 & 673 \\
\hline 19.00 & 31.00 & 107 & 0.031 & 485 \\
\hline 19.00 & 29.00 & 108 & 0.036 & 72 \\
\hline 14.00 & 34.00 & 108 & 0.037 & 361 \\
\hline
\end{tabular}




$\begin{array}{lllll}21.00 & 34.00 & 109 & 0.027 & 301 \\ 19.00 & 32.00 & 109 & 0.024 & 577 \\ 20.00 & 33.00 & 112 & 0.026 & 368 \\ 17.00 & 31.00 & 113 & 0.048 & 479 \\ 17.00 & 32.00 & 115 & 0.054 & 459 \\ 18.00 & 31.00 & 115 & 0.034 & 285 \\ 14.00 & 33.00 & 116 & 0.043 & 733 \\ 15.00 & 33.00 & 118 & 0.044 & 590 \\ 15.00 & 32.00 & 119 & 0.045 & 789 \\ 15.00 & 34.00 & 119 & 0.076 & 365 \\ 17.00 & 34.00 & 121 & 0.188 & 85 \\ 17.00 & 33.00 & 121 & 0.060 & 395 \\ 14.00 & 32.00 & 122 & 0.041 & 815 \\ 16.00 & 34.00 & 123 & 0.102 & 216 \\ 18.00 & 32.00 & 123 & 0.051 & 298 \\ 16.00 & 33.00 & 124 & 0.048 & 417 \\ 16.00 & 32.00 & 129 & 0.047 & 563 \\ 11.00 & 35.00 & 140 & 0.076 & 49\end{array}$

